\title{
The Research on the Economic Effect of Market-Based Environmental Policy Instruments
}

\author{
Yunfan Bai ${ }^{*}$, Xing Yang ${ }^{1,2}$ \\ ${ }^{1}$ Department of Finance, Jinan University, Guangzhou, China \\ ${ }^{2}$ Guangzhou College of South China University of Technology, Guangzhou, China \\ Email: *Acebyf@163.com
}

Received 14 March 2016; accepted 15 April 2016; published 18 April 2016

Copyright (C) 2016 by authors and Scientific Research Publishing Inc.

This work is licensed under the Creative Commons Attribution International License (CC BY). http://creativecommons.org/licenses/by/4.0/

(c) (i) Open Access

\begin{abstract}
Market-based environmental policy has many forms, including carbon trade and carbon taxes. The choice of market-based environmental policy instruments needs careful consideration of the effect on economy growth and structure. In the analytical framework of Ramsey model, carbon emissions are added into the instantaneous utility function and the problem of maximization of enterprise profits. Based on this hypothesis, the balance growth path and dynamitic changes of consumption and investment could be compared under different market-based environmental policy instruments. The conclusion shows that market-based environmental policy instruments have a negative effect on economic growth in the short run. However, in the long run, these instruments can promote economic growth and optimize economic structure by giving enterprises motivation to improve emission reduction technology. The distinction of these two environmental policy instruments lies in the difference between the price of carbon emission permit and the rate of carbon taxes. Moreover, by derivation, it is obvious that saving rate is inversely linked to carbon tax rate (or the price of carbon emission permit). Therefore, according to the current situation in China's economic development, in order to improve consumption's contribution on economic growth, we can choose the instrument which has higher price to reduce saving rate. In this way, consumption can be promoted and the structure of economics can be optimized.
\end{abstract}

\section{Keywords}

Market-Based Environmental Policy Instruments, Economic Growth, Consumption, Investment, Ramsey Model

\footnotetext{
*Corresponding author.
} 


\section{Introduction}

It is common seen in developed countries that governments control carbon emission by carbon polices under the background of international climate negotiation. Generally speaking, the regulation polices include direct administrative intervention and indirect market-based environmental policies. Many scholars' researches have shown that market-based environmental policies are superior to direct administrative intervention from both the economic effect and reduce emissions result. Market-based environmental policy instruments achieve the purpose of emission reduction by using market-oriented means which can effect the main market players' behavior by changing price and supply-demand relationship. Broadly speaking, market-based environmental policy tools include Coase approaches and Pigou means. The former internalizes the externality by the definition of property rights, which is typical representative by tradable emission rights while the latter uses taxes, subsidies and other ways to make the social costs and private costs of carbon emissions behavior to be the same, which is typical representative by carbon tax. For our country, as economy growth and the balance of "troika" are hot topics for government, it needs careful consideration when choosing suitable environmental policy tools as different tools have different effects on the economy growth and economy structure both in the short run and long run. From this aspect, this paper examines the balanced growth paths of carbon taxes and tradable emission rights by Ramsey model and ascertains the optimal environmental policies according to the conclusions and China's actual situation.

Among the researches about the effect of environmental policy instruments on economic growth and economic structure, using basic macroeconomic models to analyze is common seen. Most of them join environmental policy factor into the model and analyze the effect of environmental pollution, environmental policy on economic growth and economic structure. In this area, early studies mainly rely on the framework of neoclassical growth model, which are typical representative by Keeler, Spence, Zeckhauser [1] and Stiglitz [2], who considered the economic growth under the restriction of resources and environment problems by using Ramsey model. As P. Romer put forward endogenous economic growth model, more and more scholars endogenized technology progress. On this basis, they used endogenous economic growth model to consider the relationship between environmental pollution, environmental policy and economic growth. Bovenberg and Smulders [3] introduced environmental pollution and resources' endowment simultaneously into production function and consumption's utility function. This assumption is more practical than former researches. By introducing technological advances into economic growth model, their studies found that environmental policies would be detrimental to economic growth when treating environment as public consumption goods. However, when treating environment as public investment goods, environmental policies would promote long-term economic growth. Grimaud and Rouge [4] introduced resources and environment into economic growth model and found that the optimal environment tax can make economy achieve optimal growth path. Larsen and Nesbakken [5] simulated the influence of carbon tax on energy consumption and $\mathrm{CO}_{2}$ emissions in Norway and found that the influences of carbon tax for different departments are different. Lee [6] further analyzed the different environmental policy instruments. He held the view that simple carbon tax would have negative impacts on GDP, while simultaneously using carbon tax and emission trading would promote economic growth.

Among domestic researches, Xu Shichun, He Zhengxia and Wei Xiaoping [7] used optimal control method to research the sustainable optimal economic growth under steady state by endogenous economic growth model. Their study found that the ratio of intertemporal substitution elasticity of consumption, human capital accumulation efficiency and time discount rate should satisfy a certain relationship. This is an essential condition to achieve optimum and sustainable economic growth path. On this basis, Xu Shichun [8] further compared the balanced growth path and the optimal growth path. He found that using market-based environmental policy tools could correct the balanced growth path, making economy development towards the optimum and sustainable economic growth path. Wang Jinnan et al. [9] used CGE model to analyze the effect of carbon tax policy on China's economic growth, energy conservation and emissions reduction. The conclusions revealed that the highest effect of carbon tax on economic growth is $0.5 \%$, while the effect on promoting energy saving and emission reduction is increasing. Gao Pengfei, Chen Wenying, He Juhuang (Wu Zongxin, Chen Wenying, 2001; Gao Pengfei, Chen Wenying, 2002; He Juhuang, Shen Keting, Xu Haoling, 2002) [10]-[12] respectively used MARKAL and MARKAL-CGE model and CGE model to analyze the effect of carbon tax on our country's economic growth and carbon reduction. Wei Taoyuan [13] used CNAGE model which was evolved by CGE model to research the influences of carbon taxes on economic growth. The study found that GDP would decline 
by about $0.4 \%$ in the short term and $\mathrm{CO}_{2}$ emissions would fall by $8 \%$ when $\$ 5$ tax on every ton of carbon was imposed. In the long term GDP would decline by $0.1 \%$ and $\mathrm{CO}_{2}$ emissions would fall by $2 \%$. In the case of $\$ 10$ tax on per ton of carbon, GDP in the short term would decline $0.85 \%$ while $\mathrm{CO}_{2}$ emissions would fall by $14 \%$. In the long term GDP would decline by $0.07 \%$ while $\mathrm{CO}_{2}$ emissions will fall by $4 \%$. These data indicate that carbon tax has more impact on the economy and $\mathrm{CO}_{2}$ emissions in the short term than that in the long term. By using the relevant industry data of 29 provinces, municipality directly under the central government and autonomous regions, Zhang Zhixin and Li Ya [14] built panel data model and used generalized least squares method to empirically test the impact of carbon taxes on economic growth. Their research focused on the effect of carbon taxes on economic growth in different areas in our country. The conclusions revealed that the difference of effect for different areas indeed existed when carbon taxes were imposed. That is to say, carbon taxes would widen the gap of economic development between developed and developing areas. So they suggested that China should practice the discriminating carbon tax policies- the developed areas should implement high strength carbon tax policy while less developed areas should implement lower intensity carbon tax policy. Zhang Jinghua [15] used normative analysis method to analyze the economic effect of carbon taxes. He considered carbon tax policy to be an important means to solve China's environmental problem. He held the view that in the short term carbon taxes may cause certain blow to enterprise production, thus causing a certain adverse effect on economic growth. However, from the long-term perspective, he thought that imposing taxes on carbon emissions could maintain the healthy development of economy by promoting enterprise to reduce emissions. He also put forward that in order to reduce adverse effects of carbon taxes in the short term, governments could reduce other types of taxes.

By researching the related literatures, we find that although there are many papers discussing the effect of market-based environmental policy tools on economy growth, these literatures are mainly focused on carbon taxes while other market-based environmental policy tools are paid little attention. The contrastive analysis of different tools is also uncommon. Some researches involve different tools, but these researches just stay on the level of empirical analysis while in-depth theoretical analysis is not concerned. What's more, the existing literatures research little on the dynamic change of consumption and investment under balanced growth path when market-based environmental policy tools are used. Based on the shortcomings of existing researches, this paper tries to introduce the environmental pollution into consumer's utility function and simultaneously put the relationship between carbon emissions and capital introduction into producer's constraints to make the model more practical. On this basis, this paper studies the effect of different environmental policy instruments on long-term economic growth, consumption-investment structure and conducts comparative analysis. Then according to the conclusions, we put forward the corresponding policy recommendations.

\section{Model Building}

Under the analysis framework of Ramsey model, this paper introduces the environmental pollution into consumer's utility function and producer's production constraints. Firstly, the model should satisfy the basic requirements of Ramsey Model:

1) The market is completely competitive, so there are many homogeneous firms and households;

2) The company's production function is: $Y=F(K, A L)$, and the function satisfies Inada Conditions. The goal of the enterprises is in pursuit of maximization profit, and the profits shall be owned by the families;

3) The number of households is $H$, and households have infinite lifetime. The growth rate of population of every household is $n$. households provide capital inelastically and the initial capital that households own is $\frac{K(0)}{H}>0$ households pursue for maximization utility;

4) Exogenous technological progress rate are given as $g$ and there are no capital depreciation.

On these bases, this paper assumes that lifetime utility expression of households is:

$$
U=\int_{t=0}^{\infty} \mathrm{e}^{-\rho t} u[c(t)] \frac{L(t)}{H} \mathrm{~d} t
$$

In this formula, $L(t)$ is the quantity of labor force in the whole economic entity at $t$ moment. $u[c(t)]$ is the instantaneous utility function of the family. Unlike the general Ramsey model, when we consider the environmental quality, the utility level of families should not only be decided by consumption, but also environmen- 
tal pollution. So the form of instantaneous utility function is not $u(C)=\frac{C^{1-\theta}}{1-\theta}$. It should be:

$$
u(C, E)=\frac{C^{1-\theta}}{1-\theta}-\frac{E^{1+\varphi}}{1+\varphi}
$$

where $C$ is consumption of every household and $E$ are the carbon emissions of the economic entity. $\theta$ and $\varphi$ respectively measure the influence degree of consumption and carbon emissions on utility.

In order to get the balanced growth path, we need to ascertain the state that the growth rate of each variable is constant. In the framework of Ramsey model, our aim is effective capital per labor being constant. According to:

$$
\begin{gathered}
\dot{K}=I=Y-C L \\
k=\frac{K}{A L}, \quad y=\frac{Y}{A L}=f(k)
\end{gathered}
$$

We can get:

$$
\frac{\dot{k}}{k}=\frac{\dot{K}}{K}-n-g=\frac{Y-C L}{K}-n-g=\frac{y-c}{k}-n-g=0
$$

So we have:

$$
f(k)-c-(n+g) k=0
$$

We can obviously see in the above formula that in order to get $k$, we also need get the state that the growth rate of $c$ is zero. So, we need to solve optimization problems of representative households and enterprises.

\section{Model Solution}

\subsection{The Solution of Household Utility Maximization}

As consumer's utility function is given, we consider household budget constraint. households budget constraint is the sum of the discounted value of consumption during different period, which is not greater than the initial wealth value plus the sum of income discounted value of life. We express $w$ as wage rates and $r$ as interest rate while assume the capital stock at 0 moment is $K(0)$. In this condition, the capital stock that each household owns at time zero is $\frac{K(0)}{H}$. At the same time, we define $R(t)=\int_{\tau=0}^{t} r(\tau) \mathrm{d} \tau$ and use $\mathrm{e}^{-R(t)}$ to express discount factor, thus the sum of discounted income that a family owns in the whole life is $\int_{t=0}^{\infty} \mathrm{e}^{-R(t)} W(t) \frac{L(t)}{H} \mathrm{~d} t$. In the same way, the sum of discounted consumption that a family owns in the whole life is. $\int_{t=0}^{\infty} \mathrm{e}^{-((t)} C(t) \frac{L(t)}{H} \mathrm{~d} t$ So the household budget constraint can be expressed as follows:

$$
\int_{t=0}^{\infty} \mathrm{e}^{-R(t)} C(t) \frac{L(t)}{H} \mathrm{~d} t \leq \frac{K(0)}{H}+\int_{t=0}^{\infty} \mathrm{e}^{-R(t)} W(t) \frac{L(t)}{H} \mathrm{~d} t
$$

It is worth noting that as carbon emissions are public goods for consumers, the only factor that consumers need to consider when making the choice of utility maximization is the amount of consumption $(C(t))$ of each phase. In another word, the amount of emission of each phase $(E(t))$, the only influence of which for consumers is its negative effects on utility level, is not decided by consumers. So $E(t)$ only exists in households' utility function, and does not exist in the budget constraint.

As we assume that the rate of technological progress is $g$ and growth rate of population is $n$, there are $A(t)=A(0) \mathrm{e}^{g t}$ and $L(t)=L(0) \mathrm{e}^{n t}$. Because consumption per person is $C(t)=A(t) c(t)$, so the lifetime utility function of consumers can be expressed as:

$$
U=B \int_{t=0}^{\infty} \mathrm{e}^{-\beta t} \frac{c(t)^{1-\theta}}{1-\theta} \mathrm{d} t-\int_{t=0}^{\infty} \mathrm{e}^{-\rho t} \frac{E(t)^{1+\varphi}}{1+\varphi} \frac{L(t)}{H} \mathrm{~d} t
$$


where $B=\frac{A(0)^{1-\theta} L(0)}{H}$ and $\beta=\rho-n-(1-\theta) g$. Budget constraint of a family can be simplified as follows:

$$
\int_{t=0}^{\infty} \mathrm{e}^{-R(t)} c(t) \mathrm{e}^{(n+g) t} \mathrm{~d} t \leq k(0)+\int_{t=0}^{\infty} \mathrm{e}^{-R(t)} w(t) \mathrm{e}^{(n+g) t} \mathrm{~d} t
$$

The question of lifetime utility maximization for the household therefore is:

$$
\begin{gathered}
\max U=B \int_{t=0}^{\infty} \mathrm{e}^{-\beta t} \frac{c(t)^{1-\theta}}{1-\theta} \mathrm{d} t-\int_{t=0}^{\infty} \mathrm{e}^{-\rho t} \frac{E(t)^{1+\varphi}}{1+\varphi} \frac{L(t)}{H} \mathrm{~d} t \\
\text { s.t. } \int_{t=0}^{\infty} \mathrm{e}^{-R(t)} c(t) \mathrm{e}^{(n+g) t} \mathrm{~d} t \leq k(0)+\int_{t=0}^{\infty} \mathrm{e}^{-R(t)} w(t) \mathrm{e}^{(n+g) t} \mathrm{~d} t
\end{gathered}
$$

Building a Lagrange function, we can get:

$$
L=B \int_{t=0}^{\infty} \mathrm{e}^{-\beta t} \frac{c(t)^{1-\theta}}{1-\theta} \mathrm{d} t-\int_{t=0}^{\infty} \mathrm{e}^{-\rho t} \frac{E(t)^{1+\varphi}}{1+\varphi} \frac{L(t)}{H} \mathrm{~d} t+\lambda\left(\int_{t=0}^{\infty} \mathrm{e}^{-R(t)} c(t) \mathrm{e}^{(n+g) t} \mathrm{~d} t-k(0)-\int_{t=0}^{\infty} \mathrm{e}^{-R(t)} w(t) \mathrm{e}^{(n+g) t} \mathrm{~d} t\right)
$$

The first order condition therefore is:

$$
\frac{\partial L}{\partial c(t)}=B \mathrm{e}^{-\beta t} c(t)^{-\theta}-\lambda \mathrm{e}^{-R(t)} \mathrm{e}^{(n+g) t}=0
$$

Transposing the formula above and seeking partial derivative for $t$, we can get:

$$
-\beta-\theta \frac{\dot{c}(t)}{c(t)}=-r(t)+(n+g)
$$

So the growth rate of consumption is:

$$
\frac{\dot{c}(t)}{c(t)}=\frac{-\beta+r(t)-(n+g)}{\theta}=\frac{-(\rho-n-g+\theta g)+r(t)-(n+g)}{\theta}=\frac{r-\rho-\theta g}{\theta}
$$

\subsection{The Solution of Enterprise Optimization Problem}

\subsubsection{The Condition that There Is No Policy Instruments}

In the assumption of the model, the production function of an enterprise is $Y=F(K, A L)$, which satisfies Inada Conditions. On these bases, we can firstly get the optimization problem of the enterprise under the state that there is no policy instruments. That is:

$$
\max \pi=F(K, A L)-w A L-r K
$$

Under this state, there is no constraint for the optimization problem above. So we have:

$$
\frac{\partial \pi}{\partial k}=f^{\prime}(k)-r=0
$$

That is to say, the optimal condition is:

$$
r=f^{\prime}(k)
$$

This optimal condition means the marginal product of capital should be equal to the rate of return on capital, which is the same as that in the basic Ramsey model. Substituting this formula into the utility maximization problem of the household and we can get the growth rate of effective consumption per labor. That is:

$$
\frac{\dot{c}(t)}{c(t)}=\frac{f^{\prime}(k)-\rho-\theta g}{\theta}
$$

So the balanced growth path can be get from the two formulas below:

$$
\begin{aligned}
& \frac{\dot{c}(t)}{c(t)}=\frac{f^{\prime}(k)-\rho-\theta g}{\theta}=0 \\
& \dot{k}=f(k)-c-(n+g) k=0
\end{aligned}
$$




\subsubsection{The Condition that Policy Instruments Exist}

The effects of market-based environmental policy instruments on the optimization problem of the enterprise are mainly concentrated reflection in two points. Firstly, market-based environmental policy instruments effect balanced growth path by changing the return on capital. Secondly, under the condition that policy instruments exist, we should consider the constraint: $E=\alpha K$, which means there is a certain proportion between carbon emissions and capital investment. So enterprise's optimization decision can indirectly determine the amount of carbon emissions, which means carbon emission is not an exogenous variable. The coefficient $\alpha$ reflects the emission reduction technology of the enterprise. A bigger $\alpha$ reflects that the enterprise has lower reduction technology level while a smaller $\alpha$ reflects that the enterprise has higher reduction technology level.

1) Carbon tax

Assuming carbon tax rate is $t$, the optimization problem of the enterprise can be expressed:

$$
\begin{aligned}
& \max \pi=F(K, A L)-w A L-r K-t E \\
& \text { s.t. } E=\alpha K
\end{aligned}
$$

Building a Lagrange function, we can get:

$$
L_{1}=F(K, A L)-w A L-r K-t E+\lambda(E-\alpha K)
$$

Seeking partial derivative for $k$ and $E$, we can get the first order condition:

$$
\begin{aligned}
& \frac{\partial L_{1}}{\partial k}=A L f^{\prime}(k)-r A L-\lambda \alpha A L=A L\left[f^{\prime}(k)-r-\lambda \alpha\right]=0 \\
& \frac{\partial L_{1}}{\partial E}=-t+\lambda=0
\end{aligned}
$$

So the optimization problem of the enterprise under the situation of carbon taxes is:

$$
r=f^{\prime}(k)-\alpha t
$$

The balanced growth path therefore is:

$$
\begin{aligned}
& \frac{\dot{c}(t)}{c(t)}=\frac{f^{\prime}(k)-\rho-t \alpha-\theta g}{\theta}=0 \\
& \dot{k}=f(k)-c-(n+g) k=0
\end{aligned}
$$

2) Tradable emission rights

Assuming the price of tradable emission rights is $P$, and the quotas governments give enterprises are $\tilde{E}$, the optimization problem of enterprises under the situation of tradable emission rights can be expressed:

$$
\begin{aligned}
& \max \pi=F(K, A L)-w A L-r K-P(E-\tilde{E}) \\
& \text { s.t. } E=\alpha K
\end{aligned}
$$

Building a Lagrange function, we can get:

$$
L_{2}=F(K, A L)-w A L-r K-P(E-\tilde{E})+\lambda(E-\alpha K)
$$

Seeking partial derivative for $k$ and $E$, we can get the first order condition:

$$
\begin{aligned}
& \frac{\partial L_{2}}{\partial k}=A L f^{\prime}(k)-r A L-\lambda \alpha A L=A L\left[f^{\prime}(k)-r-\lambda \alpha\right]=0 \\
& \frac{\partial L_{2}}{\partial E}=-P+\lambda=0
\end{aligned}
$$

So the optimization problem of enterprises under the situation of tradable emission rights is:

$$
r=f^{\prime}(k)-\alpha P
$$

The balanced growth path therefore is: 


$$
\begin{aligned}
& \frac{\dot{c}(t)}{c(t)}=\frac{f^{\prime}(k)-\rho-P \alpha-\theta g}{\theta}=0 \\
& \dot{k}=f(k)-c-(n+g) k=0
\end{aligned}
$$

\section{Model Conclusion and Suggestion}

\subsection{Model Conclusion}

From the above analysis about the influence of carbon taxes and tradable emission rights on the balanced growth path, we can get the following conclusions.

Firstly, market-based environmental policy instruments will have a certain impact on economic growth in the short term. Under the condition of ignoring the environmental pollution, the prerequisites for balanced growth path are:

$$
\begin{aligned}
& \frac{\dot{c}(t)}{c(t)}=\frac{f^{\prime}(k)-\rho-\theta g}{\theta}=0 \\
& \dot{k}=f(k)-c-(n+g) k=0
\end{aligned}
$$

When we consider the environmental pollution and conduct market-oriented environmental policy instruments, the balanced growth path conditions under the state of imposing carbon tax are:

$$
\begin{aligned}
& \frac{\dot{c}(t)}{c(t)}=\frac{f^{\prime}(k)-\rho-t \alpha-\theta g}{\theta}=0 \\
& \dot{k}=f(k)-c-(n+g) k=0
\end{aligned}
$$

The balanced growth path conditions under the state of tradable emission rights are as follows:

$$
\begin{aligned}
& \frac{\dot{c}(t)}{c(t)}=\frac{f^{\prime}(k)-\rho-P \alpha-\theta g}{\theta}=0 \\
& \dot{k}=f(k)-c-(n+g) k=0
\end{aligned}
$$

Contrasting the above three equations, we find that consumption growth rate condition of the balanced growth path changes under the state of market-oriented environmental policy instruments. The original condition can be converted into $f^{\prime}(k)=\rho+\theta g$, while it changes to $f^{\prime}(k)=\rho+\theta g+t \alpha$ and $f^{\prime}(k)=\rho+\theta g+P \alpha$ after the implementation of market-oriented environmental policy instruments respectively. $\rho+\theta g+t \alpha$ and $\rho+$ $\theta g+P \alpha$ are both larger than $\rho+\theta g$. As $f^{\prime \prime}(k)<0$ in Inada Conditions, market-oriented environmental policy instruments will lead to the result that capital stock under steady-state level is lower than that of the original state. As mentioned above, for consumers, what they can choose is just the amount of consumption. Although the variable of environmental pollution is in the consumer's utility function, the family consumer itself cannot decide the carbon emissions. So using market-oriented environmental policy instruments cannot have impact on family decisions directly, and the second condition of balanced growth path is not changed. Putting the two equations together, we can get the dynamic effects of market-based environmental policy instruments on balanced growth path. After the market-oriented environmental policy instruments are implemented, the capital stock of balanced growth path drops, whose policy implication is that when governments implement an environmental policy (whether it is a carbon tax policy or tradable emission rights), the rate of return on capital is falling. Therefore, the capital stock of the balanced growth path declines. That is to say, investment drops. Due to $y=f(k)$, the use of environmental policy instruments will cause certain impact on economy. It means that the implementation of environmental policy instruments will change the effective capital per labor under steady state. When the economy adjusts and eventually restores the steady-state level with the impact of environmental policy, effective capital per labor drops. Therefore, effective output per labor drops means that market-oriented environmental policy instruments will produce certain impact on economic growth in the short term.

Secondly, when it comes to the effect of market-oriented environmental policy instruments on consumption and investment, the dynamic adjustment mechanism of consumption and investment is different in the short 
term. Assuming that the effective capital per labor is $k^{*}$ and effective consumption per labor is $c^{*}$ when it achieves balanced growth path, after implementing the market-oriented environmental policy instruments, $k^{*}$ and $c^{*}$ will change. However, the mechanism of change is different. Because the capital stock is decided by the past investment decisions, the capital does not change at the moment when governments announce that they begin to use market-based environmental policy instruments, and will still stay in the original balanced growth path $k^{*}$. Then due to the decline of return on capital, capital stock decreases, eventually reaching a new equilibrium. This is a continuous process. However the dynamic change mechanism of effective consumption per labor is different. As environmental policy reduces the rate of return on savings and capital accumulation, families will choose to save less and consume more. Then, in order to achieve a new equilibrium growth state, the economy will move along the path of saddle point, and finally reach a new equilibrium. Compared with the changing process of effective capital per labor, the process of the effective consumption per labor is not continuous. So we can get a two-sided conclusion about the impact of market-oriented environmental policy instruments on production and consumption in the short term. On one hand, as mentioned above, under the new equilibrium growth path, the balanced capital stock and effective consumption per labor are decreased, and the effective output per labor also falls. Therefore, the implementation of market-oriented environmental policy instruments has a certain impact on the economy. On the other hand, although the final effective consumption per labor drops, this is not a continuous process, but a process of rising sharply and declining slowly and continuously. Because consumers pursue the utility maximization of lifetime, after the implementation of environmental policy instruments, the sum of discounted consumption in each period may not be less than the original level. When households pay more attention in the current consumption, the discount factor $\rho$ is greater. Under this situation, the leap growth of consumption caused by the use of environmental policy instruments will increase the utility of household.

Thirdly, from a long-term perspective, the use of market-oriented environmental policy instruments has a strong positive impact. For enterprises, as market-based environmental policy instruments change the return of capital, they will have greater motivation to improve the technology of emission reduction for a higher return on capital. So carbon emissions of capital stock per unit will be down. In another word, $\alpha$ will down. From a long-term point of view, the effect of the reduction of $\alpha$ on the balanced growth path is making the balanced capital stock rise, which promotes the output per labor increase. Although the implementation of marketoriented environmental policy instruments will have a certain negative impact on the economy in the short run, it will promote sustainable and healthy economy development by improving the enterprise's technology of emission reduction in the long run. Meanwhile, that enterprises improve the technology of emission reduction will reduce carbon emissions. As carbon emissions have negative effects on household's lifetime utility, enterprise can improve the family utility of the lifetime by improving the technology of carbon emissions reduction. At the same time, as we have analyzed before, we can get that investment and consumption will increase under steady state as $\alpha$ declines. Therefore, it will improve the utility of household. To sum up, from the long-term perspective, using market-based environmental policy instruments will promote the sustainable growth of economy, and improve household's lifetime utility.

In the end, we can conduct comparative analysis on the economic effect of carbon tax and tradable emission rights. The difference of influence that two kinds of policy instruments have on balanced growth path lies in the containing factors in the balanced growth path. That is to say, carbon tax include $t$ and $\alpha$, while tradable emission rights include $P$ and $\alpha$. So the essential difference is the carbon tax rate and the price of tradable emission rights. When carbon tax rate is larger than the price of tradable emission rights, the capital stock under the situation of carbon tax is lower than that of tradable emission rights as the first prerequisite in balanced growth path shows. Whereas, when carbon tax rate is smaller than the price of tradable emission rights, the capital stock under the situation of carbon tax is higher than that of tradable emission rights. In a word, capital stock is inversely proportional to tradable emission rights or carbon tax rate.

\subsection{Suggestions}

As we have analyzed before, market-based environmental policy instruments have corrective effect on economic growth in the long run while have negative effect on investment and output in the short term. So when considering using environmental policy instrument, we should balance the long-term effects and short-term results to reduce the adverse impacts environmental policy instruments brings. It's of great value to conduct environmen- 
tal polices based on the thoughts of adjusting economic structure. As our country's economy relies too much on investment while consumption contributes less to economy, it's of great importance to improve the level of consumption for healthy development of the economy. Under the balanced growth path, we have:

$$
f(k)-c=(n+g) k
$$

And saving rate can be expressed as:

$$
s=\frac{f(k)-c}{f(k)}
$$

So there is the following equation:

$$
s=\frac{(n+g) k}{f(k)}
$$

Taking derivative of carbon tax rate (the price of carbon emission rights) on both side of the equation, we can get:

$$
\frac{\partial s}{\partial t}=\frac{(n+g)(\partial k / \partial t) f(k)-(n+g) k f^{\prime}(k)(\partial k / \partial t)}{f(k)^{2}}
$$

This equation can be rewritten as:

$$
\frac{\partial s}{\partial t}=\frac{(n+g)(\partial k / \partial t)}{f(k)}\left[1-\frac{k f^{\prime}(k)}{f(k)}\right]
$$

As $\frac{\partial k}{\partial t}<0, \frac{k f^{\prime}(k)}{f(k)}$ which represents the income share of the capital is greater than 0 and less than 1 . For this reason, saving rate is inversely proportional to carbon tax rate(the price of carbon emission rights). This conclusion give us the following enlightenment: when choosing market-based environmental policy instruments, in order to reduce the savings rate to promote consumption, we can choose the policy which has higher price. Although the higher price policy will have a negative effect on the capital stock as above analysis has revealed, the implementation of market-oriented environmental policy instruments will have a positive impact for longterm economic growth. But high price policy in the short term will reduce consumers' savings rate, so as to stimulate consumption and improve consumers' life utility. In practice, therefore, it should be to determine the carbon tax rate policy of the government intends to make, and find the carbon price in the carbon exchange market, and then compare them to determine the optimal environmental policy instruments.

\section{References}

[1] Keeler, E., Spence, M. and Zeckhauser, R. (1971) The Optimal Control of Pollution. Journal of Economic Theory, 4, 19-34. http://dx.doi.org/10.1016/0022-0531(72)90159-7

[2] Stiglitz, J. (1974) Growth with Exhaustible Natural Resources: The Competitive Economy. The Review of Economic Studies, 41, 139-152. http://dx.doi.org/10.2307/2296378

[3] Bovenberg, A. and Smulders, S. (1995) Environmental Quality and Pollution-Saving Technological Change in a TwoSector Endogenous Growth Model. Journal of Public Economics, 57, 369-391. http://dx.doi.org/10.1016/0047-2727(95)80002-Q

[4] Grimaud, A. and Rouge, L. (2005) Polluting Non-Renewable Resources, Innovation and Growth: Welfare and Environmental Policy. Resource and Energy Economics, 27, 109-129. http://dx.doi.org/10.1016/j.reseneeco.2004.06.004

[5] Larsen, B.M. and Nesbakken, R. (1997) Norweigian Emissions of $\mathrm{CO}_{2}$ 1987-1994: A Study of Some Effects of the $\mathrm{CO}_{2}$ Tax. Environmental and Resource Economics, 9, 275-290. http://dx.doi.org/10.1007/BF02441400

[6] Lee, C.F., Lin, S.J. and Lewis, C. (2008) Analysis of the Impacts of Combining Carbon Taxation and Emission Trading on Different Industry Sectors. Energy Policy, 36, 722-729. http://dx.doi.org/10.1016/j.enpol.2007.10.025

[7] Xu, S.C., He, Z.X. and Wei, X.P. (2010) Sustainable Optimal Economic Growth Path under Resource Consumption and Pollution Control. Journal of management science in China, 13, 20-30.

[8] Xu, S.C. (2012) Study on Influential Mechanism on Carbon Abatement and Optimization of Market-Based Environ- 
mental Policy Instruments. PhD Thesis, China University of Mining and Technology, Beijing.

[9] Wang, J.N., et al. (20090 The Study on China's Carbon Tax Policy to Mitigate to Climate Change. China Environmental Science, 29, 101-105.

[10] Chen, W.Y. and Wu, Z.X. (2001) Study of China's Sustainable Energy Development Strategy in the Future Using MARKAL Model. Journal of Tsinghua University (Science and Technology), 41, 103-106.

[11] Gao, P.F. and Chen, W.Y. (2002) Carbon Tax and Carbon Emissions. Journal of Tsinghua University (Science and Technology), 42, 1335-1338.

[12] He, J.H., Shen, K.T. and Xu, H.L. (2002) The CGE Model of Carbon Tax and $\mathrm{CO}_{2}$ Emission. Journal of Quantitative \& Technical Economics, 10, 39-47.

[13] Wei, T.K. and Gromsload, S. (2002) The Effect of Carbon Tax on China’s Economy and Greenhouse Gas Emissions. World Economics and Politics, 8, 47-49.

[14] Zhang, Z.X. and Li, Y. (2011) Effects of Carbon Tax on Chinese Economic Growth and Industrial Development. Journal of Zhongnan University of Economics and Law, 189, 44-49.

[15] Zhang, J.H. (2010) Analysis on the Economic Effect of Carbon Taxes. Modern Economic Research, 2, 87-88. 